Oikos 122: 1473-1482, 2013

doi: $10.1111 / j .1600-0706.2013 .00243 . x$

(C) 2013 The Authors. Oikos (C) 2013 Nordic Society Oikos

Subject Editor: Jotaro Urabe. Accepted 1 March 2013

\title{
Parasites as prey in aquatic food webs: implications for predator infection and parasite transmission
}

\author{
David W. Thieltges, Per-Arne Amundsen, Ryan F. Hechinger, Pieter T. J. Johnson, Kevin D. Lafferty, \\ Kim N. Mouritsen, Daniel L. Preston, Karsten Reise, C. Dieter Zander and Robert Poulin
}

D.W. Thieltges (david.thieltges@nioz.nl),Dept of Marine Ecology, NIOZ Royal Netherlands Inst. for Sea Research, PO Box 59, NL-1790 AB Den Burg Texel, the Netherlands. - P.-A. Amundsen, Dept of Arctic and Marine Biology, Faculty of Biosciences, Fisheries and Economics, Univ. of Tromsø, NO-9037 Tromsø, Norway. - R. F. Hechinger, Marine Science Inst. and Dept of Ecology, Evolution and Marine Biology, Univ. of California, Santa Barbara, CA 93106, USA. - P. T. J. Johnson and D. L. Preston, Ecology and Evolutionary Biology, Univ. of Colorado, Ramaley N122, Campus Box 334, Boulder, CO 80309, USA. - K. D. Lafferty, Western Ecological Research Center, US Geological Survey. co Marine Science Inst., UC, Santa Barbara, CA 93106, USA. - K. N. Mouritsen, Dept of Biological Sciences, Marine Ecology, Aarhus Univ., Ole Worms Allé 1, DK-8000 Aarhus C, Denmark. - K. Reise, Alfred Wegener Inst. for Polar and Marine Research, Wadden Sea Station Sylt, Hafenstrasse 43, DE-25992 List/Sylt, Germany. - C. D. Zander, Biozentrum Grindel und Zoologisches Museum, Martin-Luther-King-Platz 3, DE-20146 Hamburg-Rotherbaum, Germany. - R. Poulin, Dept of Zoology, Univ. of Otago, PO Box 56, Dunedin 9054, New Zealand.

\begin{abstract}
While the recent inclusion of parasites into food-web studies has highlighted the role of parasites as consumers, there is accumulating evidence that parasites can also serve as prey for predators. Here we investigated empirical patterns of predation on parasites and their relationships with parasite transmission in eight topological food webs representing marine and freshwater ecosystems. Within each food web, we examined links in the typical predator-prey sub web as well as the predator-parasite sub web, i.e. the quadrant of the food web indicating which predators eat parasites. Most predatorparasite links represented 'concomitant predation' (consumption and death of a parasite along with the prey/host; 58-72\%), followed by 'trophic transmission' (predator feeds on infected prey and becomes infected; 8-32\%) and predation on free-living parasite life-cycle stages (4-30\%). Parasite life-cycle stages had, on average, between 4.2 and 14.2 predators. Among the food webs, as predator richness increased, the number of links exploited by trophically transmitted parasites increased at about the same rate as did the number of links where these stages serve as prey. On the whole, our analyses suggest that predation on parasites has important consequences for both predators and parasites, and food web structure. Because our analysis is solely based on topological webs, determining the strength of these interactions is a promising avenue for future research.
\end{abstract}

Food webs depict the network of feeding relationships within ecological communities. During the last few decades, a large body of food-web theory has sought to generalize food-web patterns and processes (Cohen 1978, Pimm et al. 1991, Williams and Martinez 2000, Dunne 2006, Allesina et al. 2008). Simple summary parameters used to characterize food webs include species richness $(\mathrm{S})$, the number of realised links $(\mathrm{L})$, vulnerability (the number of consumer links per resource), generality (the number of resource links per consumer), and connectance, which is the proportion of realised links out of the total number of possible links (often expressed as L/S). The relationship among these measures and their role in the stability of ecosystems has long been of interest to ecologists (May 1973, Dunne et al. 2005). However, most previous food-web studies have neglected what is perhaps the most frequent trophic interaction - parasitism (Marcogliese and Cone 1997). Recent efforts to include the missing parasite links in food-web studies have shown that adding parasitehost links to conventional predator-prey food webs increases food chain length, and may increase connectance and nestedness (Huxham et al. 1995, Thompson et al. 2005, Lafferty et al. 2006a, b, Hernandez and Sukhdeo 2008, Amundsen et al. 2009). Given that diversity, connectance, and food chain length have all been hypothesized to influence stability, these observations raise the intriguing possibility that parasites play a 'hidden' role in mediating ecosystem stability (Dobson et al. 2006, Wood 2007, Lafferty et al. 2008).

While parasites as consumers can markedly affect foodweb topologies, there is accumulating evidence that parasites can also serve as prey for predators (Johnson et al. 2010). Predation on parasites can take various forms and is probably much more significant in food webs than is indicated by its typical neglect (Johnson et al. 2010). There are two main routes by which parasites become prey. First, parasites become prey when their current host is consumed by a predator that is not a suitable down-stream host (i.e. the next host in the parasite's life cycle). In this case, predation leads to the consumption and most likely digestion of the parasite 
along with the prey (concomitant predation; Johnson et al. 2010). Second, parasites can become prey when their freeliving stages are eaten by predators (Thieltges et al. 2008a, Johnson et al. 2010, Johnson and Thieltges 2010). While there exist a few other routes by which parasites become prey, these are relatively rare. It is important to note that predation is not always fatal for parasites. Trophically transmitted parasites depend on the predation of their current hosts to infect down-stream hosts and thus exploit predatorprey links (Marcogliese and Cone 1997, Lafferty 1999). Hence, for trophically transmitted parasites, predation and transmission are inextricably linked.

The interplay of predation on parasites and parasite transmission should have important implications for both predators and parasites in food webs (Johnson et al. 2010). For predators, the greater a predator's generality (i.e. its diet breadth), the greater the probability it will consume a variety of parasites via concomitant predation. At the same time, generalist predators could become infected by more trophically transmitted parasite species compared with more specialized predators (Chen et al. 2008, Rossiter and Sukhdeo 2011). For parasites, concomitant predation or predation on free-living life-cycle stages might be an important source of mortality and regulate parasite population size, which, in turn, might result in reduced disease risk for hosts (Anderson et al. 1978). For parasites in food webs, predation (in terms of vulnerability and not absolute predation levels) might be positively linked to predator richness as the chances that a given parasite will fall within the prey spectrum of at least one predator likely increases with the number of predator species. However, some parasites require their host to be preyed upon to complete their life cycle (i.e. trophic transmission). In fact, Lafferty et al. (2006a) found that one third of predator-parasite links in the Carpinteria Salt Marsh food web led to transmission to a down-stream host. Although these processes have important implications for predators and parasites, few food-web studies have examined single predator-parasite sub webs in more detail (Lafferty et al. 2006a, Amundsen et al. 2009) or looked at the specific aspect of host network position and parasite richness without detailed analyses of predator-parasite sub webs (Chen et al. 2008, Rossiter and Sukhdeo 2011). Hence, empirical generalisations of how predation and transmission of parasites are coupled in food webs are missing, a void we attempt to fill here.

In this study, we quantify predation on parasites and its relationship with parasite transmission using a comparative approach for eight different topological food webs from marine and freshwater ecosystems with high parasite diversity. We focus on measures of vulnerability (the number of predator species that feed on a parasite species or life cycle stage) and generality (the number of resource items used by a consumer, 'diet breadth'), both common measures in foodweb studies. Using the predator-prey and predator-parasite sub webs of the eight food webs, we aim to investigate some general patterns of predation on parasites and its relationship with parasite transmission from the perspective of 1 ) the predators, 2) the parasites, and 3) the whole food web. First, we ask how predation on parasites and parasite transmission are linked from a predator's perspective by investigating whether the frequency of parasite consumption via concomitant predation increases with a predator's generality, and whether generalist predators face a higher vulnerability to infection by trophically transmitted parasites than specialist predators. Second, we look at the importance of predation on parasites from the perspective of parasites by determining the overall vulnerability of parasites in the food webs. And third, we analyse the interplay of predation on parasites and parasite transmission at the level of entire food webs by investigating whether the vulnerability of parasites and trophic transmission are linked to predator richness of the entire food web. Our study is among the first empirical quantifications of general patterns of predation on parasites and transmission in real food webs. The results of this study will foster a better understanding of the functioning of ecological networks and can subsequently be used for the development of better food-web models.

\section{Methods}

For all analyses, we used eight topological food webs that included both a predator-prey and a predator-parasite sub web. A predator-prey sub web encompasses all feeding links of predators to their prey, the type of web commonly used in food-web studies that do not include parasites. A predator-parasite sub web denotes all feeding links of predators on parasites (e.g. by feeding on infected prey). Two other sub-webs of parasite-inclusive food webs (for details see Lafferty et al. 2008) were not used in our analysis: parasitehost (denoting the feeding links of parasites to their hosts) and parasite-parasite (denoting feeding links between parasites, e.g. hyperparasitism).

Two of the food webs are from marine intertidal systems (Otago Harbour, New Zealand (Mouritsen et al. 2011); List Tidal Basin, Germany/Denmark (Thieltges et al. 2011)), one food web is from a shallow brackish water system (Flensburg Fjord, Germany/Denmark (Zander et al. 2011)), three food webs are from North American Pacific coast estuaries (Carpinteria Salt Marsh, USA; Estero de Punta Banda, Mexico; Bahía Falsa in Bahía San Quintín, Mexico (Lafferty et al. 2006a, b, Hechinger et al. 2011)), and two others are from freshwater lake or pond systems (Lake Takvatn, Norway (Amundsen et al. 2009); Quick Pond, USA (Preston et al. 2012)). All webs were assembled using data from field sampling and literature surveys (see the original publications for details) and consist of interaction matrices denoting species interactions (predator-prey and parasite-host sub-webs) but not including interaction strength (topological webs). Information on predator-parasite links was available directly from the webs or could be logically inferred by using the other two sub-webs (predator-prey and parasite-host sub-webs): a predator is assumed to eat all the parasites that infect its prey and the parasite-host sub web can be used to categorise the links as either transmission and predation links.

While interactions in the predator-prey sub webs noted only the presence or absence of predation links, entries in the predator-parasite sub webs distinguished between six types of links: 1) trophic transmission: a predator preys on infected prey and becomes infected with a parasite, thus leading to the parasite transmitting to the next host in its life cycle (down-stream host), 2) concomitant predation: a 
predator preys on infected prey but kills the parasite and does not become infected because it is not a suitable host, 3 ) predation on free-living stages: a predator preys on free-living non-feeding stages of a parasite, e.g. on trematode cercariae, and this does not lead to transmission, 4) predation on commensal stages: a predator preys on commensal non-feeding stages of a parasite, e.g. trematode metacercariae attached to sea grass blades, 5) trophic transmission via free-living parasite stage: a predator becomes infected by preying on a free-living parasite life-cycle stages, e.g. trematode cercariae infecting a fish predator when it preys on them; and 6) direct predation on parasitic plants: a predator directly preys on a parasitic plant, i.e. not on its free-living stages or indirectly via concomitant predation.

We initially used these six link types to quantify the various ways that parasites interact with predation. For subsequent analyses, either all types of predation on parasites were subsumed under predation on parasites (concomitant predation, predation on free-living stages, predation on commensal stages, direct predation on parasitic plants) to distinguish them from trophic transmission links, or analyses were conducted with specific link types of interest (concomitant predation, predation on free-living stages or trophic transmission). For all eight food webs, this link type information was available for each parasite life-cycle stage as parasite species were split into life-cycle stages in all predator-parasite sub webs. In contrast, predator species were split into life-cycle stages for a few species in the predator-prey sub webs for only the three North American Pacific coast estuary webs; for the other five webs this information was not available. This imbalance in resolution between predator-prey and predator-parasite sub webs needs to be considered when directly comparing food-web measures of the two sub webs. However, for our main purpose, i.e. to analyse the relationships of predation on parasites and parasite transmission, a high resolution of the life-cycle stages of the parasites is necessary to be able to disentangle the various types of predation. In contrast, the level of life-cycle stage resolution of predators is not relevant for our analyses as a predator simply acts as a predator of parasites no matter what life-cycle stage it is.

As a first step, we calculated food-web summary statistics for the eight webs. We determined the total number of freeliving species (basal taxa plus predators, $S$ ) as well as parasite species or life-cycle stages $(\mathrm{P})$ in each food web and calculated the number of realised or observed $\left(\mathrm{L}_{\mathrm{o}}\right)$ and potential $\left(\mathrm{L}_{\mathrm{p}}\right)$ links for each of the predator-prey $\left(\mathrm{L}_{\mathrm{p}}=\mathrm{S} \times \mathrm{S}\right)$ and predator-parasite $\left(\mathrm{L}_{\mathrm{p}}=\mathrm{S} \times \mathrm{P}\right)$ sub webs. Using the link data, we calculated connectance as $\mathrm{C}=\mathrm{L}_{\mathrm{o}} / \mathrm{L}_{\mathrm{p}}$ for each of the predator-prey and predator-parasite sub webs. In addition, we determined the proportion of the six previously mentioned link types in the predator-parasite sub webs.

To determine whether the chance of consuming parasites via concomitant predation increases for predators as a function of their prey range (predator generality), we regressed the number of concomitant predation links per predator in the predator-parasite sub web against the number of prey species consumed by each predator in the predator-prey sub web. To investigate whether generalist predators (broad prey range) had more predator-parasite links that led to infection with trophically transmitted parasites, we regressed the number of transmission links in the predator-parasite sub web against the number of prey species consumed by each predator in the predator-prey sub web. This analysis only included predators that served as down-stream hosts for at least one trophically transmitted parasite species. This criterion was used a proxy for suitable hosts to avoid including many predators belonging to taxa that are, in general, not used as hosts by trophically transmitted parasites. For both analyses (concomitant predation and parasite transmission), in addition to separate linear regressions for each web, we also tested for an overall effect of predator generality on concomitant predation or parasite transmission by running two general linear models (GLM) on the combined datasets with predator generality and food web identity as factors (after using residual plots to check for normality and homoscedasticity of the data).

To estimate the vulnerability of individual parasite life-cycle stages, we calculated the mean number of predators per parasite life-cycle stage for each food web (including life-cycle stages with no predators). In addition, we calculated the proportion of links in the predator-parasite sub web leading to transmission for all trophically transmitted parasites (trophic transmission vs concomitant predation links).

Finally, we tested whether the mean vulnerability of parasite life-cycle stages (predation on free-living stages and concomitant predation) in a food web was related to the total predator richness of the web. This analysis evaluated the number of likely predators of a given parasite stage, which relates to food-web connectance, rather than the likelihood or intensity of predation on that stage (actual interaction strength). In addition, we investigated whether the mean number of trophic transmission links per trophically transmitted stage was related to the total predator richness of the web. We did this using linear regression and mean values for each web as data points, correcting for the actual number of parasite life-cycle stages or trophically transmitted stages of each web in an effort to control for the scale-dependence of these measures with food web size. As other types of predation on parasites were very rare or absent in the eight webs, we did not investigate their relationship with predator richness.

\section{Results}

The eight food webs included 37 to 163 free-living species or life-cycle stages, with 29 to 144 of them acting as predators, the remaining being basal taxa like plants. In addition, the webs included 30-190 parasite life-cycle stages (Table 1). Connectance varied widely in both the predator-prey (0.059-0.250) and the predator-parasite (0.075-0.231) sub webs (Table 1). In all eight food webs, most links in the predator-parasite sub webs were concomitant predation links (59-72\%), followed by links leading to transmission $(8-32 \%)$, predation on free-living parasite stages (4-30\%) and very low proportions of the remaining link types (Table 1 ).

The number of concomitant predation links increased with a predator's generality, as indicated by the GLM including food web as a co-factor, i.e. predators with 
Table 1. Summary web metrics for the eight food webs, showing the number of free-living species (basal taxa and predators) and the number of predators as well as the number of parasite life-cycle stages per web, the number of realised and potential links and the resulting connectance for the predator-prey and predator-parasite sub webs, the proportion (\%) of six types of predation links in the predator-parasite sub web and the mean proportion (\%) of links ( \pm SE) leading to transmission per trophically transmitted parasite life-cycle stage.

\begin{tabular}{|c|c|c|c|c|c|c|c|c|}
\hline Web metrics & $\begin{array}{l}\text { Otago } \\
\text { Harbour }\end{array}$ & $\begin{array}{l}\text { Sylt Tidal } \\
\text { Basin }\end{array}$ & $\begin{array}{l}\text { Flensburg } \\
\text { Fjord }\end{array}$ & $\begin{array}{l}\text { Carpinteria } \\
\text { Salt Marsh }\end{array}$ & Bahia Falsa & $\begin{array}{c}\text { Estero de } \\
\text { Punta Banda }\end{array}$ & $\begin{array}{l}\text { Takvatn } \\
\text { Lake }\end{array}$ & Quick Pond \\
\hline No. free-living species & 123 & 126 & 77 & 124 & 137 & 163 & 37 & 48 \\
\hline No. of predators & 119 & 120 & 71 & 110 & 114 & 144 & 29 & 42 \\
\hline No. of parasite life cycle stages & 57 & 104 & 103 & 147 & 151 & 190 & 30 & 34 \\
\hline \multicolumn{9}{|l|}{ Predator-prey sub web } \\
\hline Realised no. of links & 1206 & 1052 & 579 & 1006 & 1104 & 1694 & 198 & 576 \\
\hline Potential no. of links & 15129 & 15876 & 5929 & 15376 & 18769 & 26569 & 1369 & 2304 \\
\hline Connectance & 0.080 & 0.066 & 0.098 & 0.065 & 0.059 & 0.064 & 0.145 & 0.250 \\
\hline \multicolumn{9}{|l|}{ Predator-parasite sub web } \\
\hline Realised no. of links & 525 & 1655 & 669 & 2027 & 1903 & 3280 & 180 & 377 \\
\hline Potential no. of links & 7011 & 13104 & 7931 & 18228 & 20687 & 30970 & 1110 & 1632 \\
\hline Connectance & 0.075 & 0.126 & 0.084 & 0.111 & 0.092 & 0.106 & 0.162 & 0.231 \\
\hline \multicolumn{9}{|l|}{ Proportion link types } \\
\hline \% Concomitant predation & 62.5 & 58.8 & 71.8 & 59.5 & 58.1 & 61.8 & 65.6 & 62.3 \\
\hline$\%$ Trophic transmission & 19.9 & 23.5 & 16.6 & 25.8 & 32 & 17.6 & 30 & 8 \\
\hline$\%$ Predation on free-living stages & 16.8 & 16.7 & 11.6 & 14.5 & 9.7 & 20.5 & 4.4 & 29.7 \\
\hline$\%$ Predation on commensal stages & 0.8 & 1 & & & & & & \\
\hline$\%$ Direct predation no transmission & & & & 0.1 & & & & \\
\hline$\%$ Direct predation transmission & & & & 0.1 & 0.2 & 0.1 & & \\
\hline $\begin{array}{l}\% \text { links leading to transmission in } \\
\text { trophically transmitted stages }\end{array}$ & $44.3 \pm 5.6$ & $60.9 \pm 4$ & $70.2 \pm 6.5$ & $64.8 \pm 4.2$ & $62.5 \pm 4.0$ & $53.9 \pm 3.9$ & $79.3 \pm 6.8$ & $59.1 \pm 13$ \\
\hline
\end{tabular}

broad prey ranges showed higher numbers of concomitant predation links than predators with narrow prey ranges (Fig. 1, Table 2). However, the significance of food-web identity indicated that levels of concomitant predation differed among webs. Overall, predators ingested 0.3-1.2 parasite species for each prey type, given the slopes from the seven significant separate linear regressions (Fig. 1, Table 3).

Predators with wide diet breadths (high predator generality) served as hosts for more trophically transmitted parasites than predators with narrow diet breadths, as indicated by the GLM (Fig. 2, Table 2). The significance of food-web identity indicated differences in the levels of parasite transmission among the webs. Overall, predators acquired 0.2-0.7 trophically transmitted parasites for each additional new prey type added to their prey range, as indicated by the slopes of the six significant separate linear regressions (Fig. 2, Table 3). In the Quick Pond food web this relationship was marginally non-significant, whereas it was non-significant in the Otago web (Fig. 2, Table 3).

The mean number of predators per parasite life-cycle stage (including stages with no predators) ranged from 4.2 to 14.2 among the different food webs (Fig. 3). Overall, trophically transmitted parasite stages used $44-79 \%$ of the links in the predator-parasite sub webs for transmission to their down-stream hosts (Table 1). These figures are higher than the percentages of trophic transmission in Table 1 because only parasite life-cycle stages that are trophically transmitted (e.g. trematode metacercariae) to a down-stream host were considered in this analysis.

When looking at the entire food web, parasite vulnerability (i.e. number of predator species consuming a parasite and not actual predation rates) tended to increase in predator-rich systems (Fig. 4), but this relationship was only significant for the vulnerability to concomitant predation for all life-cycle stages $\left(r^{2}=0.60, p=0.025\right.$; Fig. $\left.4 b\right)$ and for trophically transmitted stages $\left(\mathrm{r}^{2}=0.89 ; \mathrm{p}<0.001\right.$; Fig. $\left.4 \mathrm{c}\right)$. It was marginally insignificant for vulnerability of free-living stages $(p=0.097$; Fig. 4a). The number of trophic transmission links per trophically transmitted stage also significantly increased with predator richness of a web $\left(r^{2}=0.59\right.$, $p=0.026$; Fig. 4d). Overall, the number of trophic transmission links of trophically transmitted parasite life-cycle stages increased at approximately the same rate as their vulnerability.

\section{Discussion}

Our analyses facilitated a numerical investigation of the interplay between predation on parasites and parasite transmission in eight topological food webs. The observed patterns had previously not been verified nor quantified in multiple food webs. We showed that all webs have predator-parasite sub webs of considerable size. The separation of parasite species into life stages increased the number of potential predator-parasite links such that a direct comparison of their connectance with predator-prey links is not appropriate, but this is beyond the scope of the questions addressed here. Partitioning parasites into life-cycle stages contributes valuable additional information because the type of link in the predator-parasite sub web often differs among the life-cycle stages of a given parasite species. For example, for a trophically transmitted stage of a parasite species, many links might be transmission links, whereas for its free-living stages these are almost entirely predation links. In addition, the different life-cycle stages of a parasite may represent very different kinds of prey. For example, predation on freeliving larval stages will offer a different quality of food for a predator compared to concomitant predation on the adult stages of the same parasite species. 

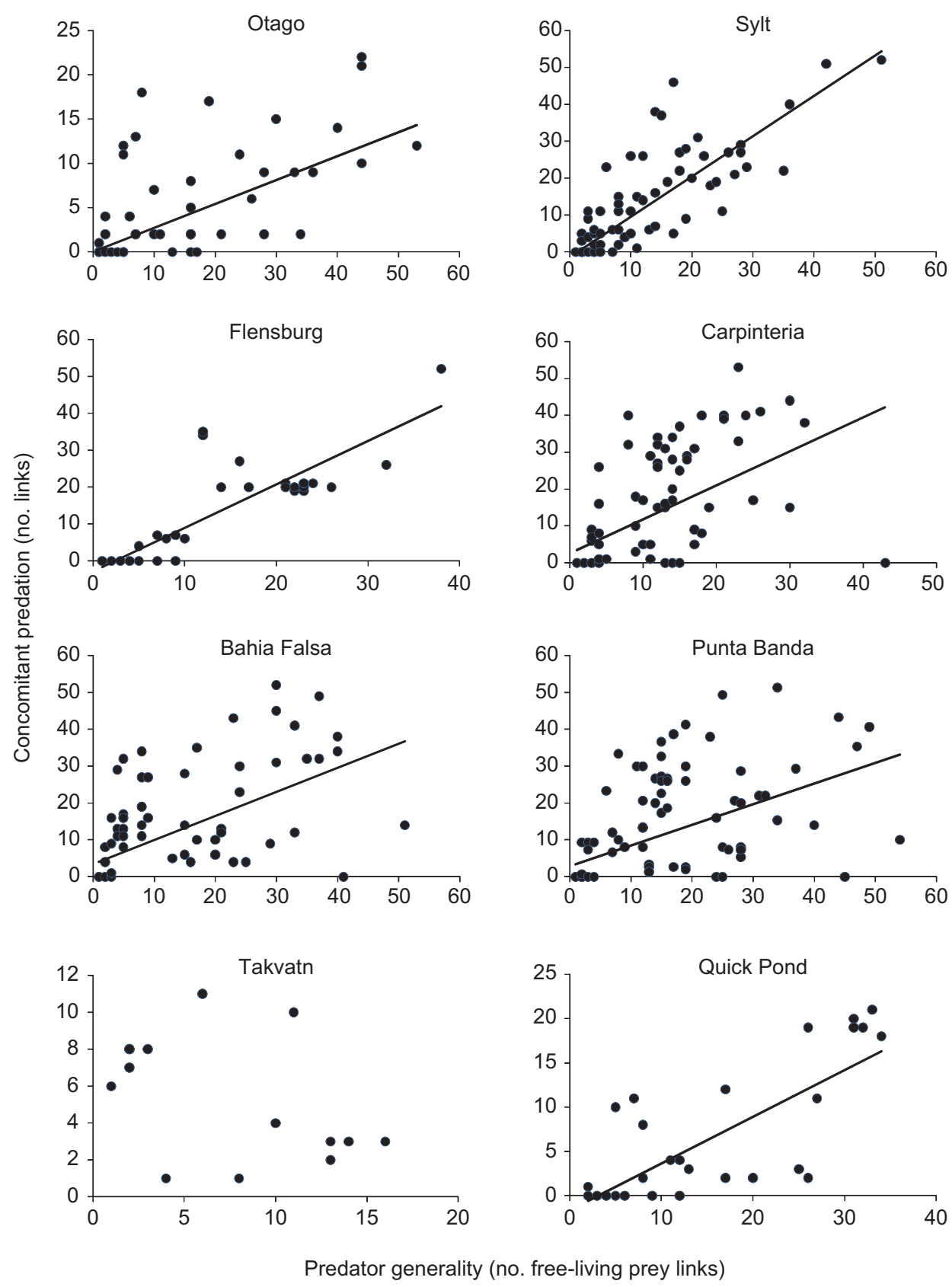

Figure 1. Relationship between predator generality (no. prey species per predator in predator-prey sub web) and the number of concomitant predation links a predator incurs by consuming parasites while preying on free-living prey. Data based on all predators in the respective webs. Note the different scales on axes. Lines indicate the best fit of significant regressions (Otago: $y=0.020+0.270 x ;$ Sylt: $y=-1.483+1.094 x$; Flensburg: $y=-2.838+1.177 x$; Carpinteria: $y=2.546+0.921 x$; Bahia Falsa: $y=3.364+0.654 x$; Punta Banda: $\mathrm{y}=4.191+0.841 \mathrm{x}$; Quick Pond: $\mathrm{y}=-1.654+0.529 \mathrm{x})$. Regression statistics and sample sizes in Table 3.

Overall, most links in the predator-parasite sub webs involved concomitant predation (Table 1). It is remarkable that this pattern was similar in all eight food webs despite the considerable differences among the systems, which ranged from marine to freshwater and from mainly benthic to mainly pelagic webs, and also vary in the number and types of parasites included. This suggests that concomitant predation on parasites is a defining feature of food-web structure. How this affects energy flow in food webs remains to be seen. With some important exceptions (e.g. high biomass trematode infections in snails or certain tapeworms in fishes), the fraction of energy gained from parasites inside a prey item will often be negligible. More important is the potential for parasites to increase predation rates on infected prey. For instance, in the three west coast estuarine webs, killifish infected with trematode metacercariae are 10-30 times more likely to be eaten by birds than are uninfected killifish (Lafferty and Morris 1996). It is also possible that parasite infections alter the energetic value of infected prey (Mouritsen and Jensen 2006, Sánchez et al. 2009). Parasites 
Table 2. Results of GLMs with predator generality and food-web identity as factors and levels of concomitant predation or parasite transmission as response variable. The tests are based on data presented in Fig. 1 and 2. DF: degrees of freedom, MS: mean squares, F: f-statistics and p: significance level.

\begin{tabular}{lrrrc}
\hline & DF & \multicolumn{1}{c}{ MS } & F & p \\
\hline Concomitant predation (Fig. 1) & & & & \\
$\quad$ Predator generality & 1 & 45834.78 & 407.66 & $<0.001$ \\
$\quad$ Food-web & 7 & 1352.17 & 12.03 & $<0.001$ \\
$\quad$ Error & 740 & 112.43 & & \\
Parasite transmission (Fig. 2) & & & & \\
$\quad$ Predator generality & 1 & 1953.31 & 46.97 & $<0.001$ \\
$\quad$ Food-web & 7 & 284.77 & 6.85 & $<0.001$ \\
$\quad$ Error & 272 & 41.59 & & \\
\hline
\end{tabular}

can also contribute energy to food webs via the production of free-living stages, many of which were eaten in the food webs analysed. Here, the parasite comprises the entire meal. Many free-living species are known to prey on free-living stages of parasites with high consumption rates (Thieltges et al. 2008a, Johnson and Thieltges 2010) and the production of some free-living stages of parasites like trematode cercariae has been shown to be high in marine, estuarine and freshwater ecosystems (Thieltges et al. 2008b, Kuris et al. 2008, Preston et al. 2013). However, it is unclear how much free-living stages actually contribute to the diet of predators (but see Kaplan et al. 2009). Overall, predation on parasites in its various forms might represent a substantial unrecognised path of energy flow through food webs that deserves further attention.

The high proportion of concomitant predation links in the eight food webs is also reflected at the level of individual predators for which it adds a significant number of prey nodes to their diets (Fig. 1). Within a particular food web, a large part of the differences in the numbers of parasite predation links among predators can be ascribed to the generality of a predator. The positive relationship between the number of concomitant predation links and predator generality (Fig. 1) suggests that generalist predators have a higher chance of consuming parasites.

Table 3. Results of simple linear regressions of the relationship between predator generality (no. of prey species preyed upon per predator species in predator-prey sub web) and 1) concomitant predation of parasites by a predator (no. of links in predatorparasite sub web; Fig. 1) and 2) parasite transmission to a (vertebrate) predator (no. links in predator-parasite sub web; Fig. 2). For each regression, the no. of nodes is given in a separate column (n).

\begin{tabular}{|c|c|c|c|c|c|c|}
\hline \multirow[b]{2}{*}{ Food web } & \multicolumn{3}{|c|}{$\begin{array}{c}\text { Concomitant } \\
\text { predation }\end{array}$} & \multicolumn{3}{|c|}{$\begin{array}{c}\text { Parasite } \\
\text { transmission }\end{array}$} \\
\hline & $r^{2}$ & $\mathrm{p}$ & $\mathrm{n}$ & $r^{2}$ & $\mathrm{p}$ & $\mathrm{n}$ \\
\hline Otago Harbour & 0.409 & $<0.001$ & 119 & 0.129 & 0.110 & 21 \\
\hline List Tidal Basin & 0.720 & $<0.001$ & 120 & 0.552 & $<0.001$ & 43 \\
\hline Flensburg Fjord & 0.749 & $<0.001$ & 71 & 0.437 & 0.004 & 17 \\
\hline Carpinteria Salt Marsh & 0.345 & $<0.001$ & 110 & 0.129 & 0.008 & 53 \\
\hline Bahia Falsa & 0.367 & $<0.001$ & 114 & 0.116 & 0.012 & 53 \\
\hline Punta Banda & 0.296 & $<0.001$ & 144 & 0.088 & 0.017 & 64 \\
\hline Takvatn Lake & 0.116 & 0.071 & 29 & 0.647 & $<0.001$ & 16 \\
\hline Quick Pond & 0.613 & $<0.001$ & 42 & 0.281 & 0.051 & 14 \\
\hline
\end{tabular}

However, being a generalist may also expose predators to higher numbers of parasite species (given that they are suitable hosts) because the number of trophically transmitted parasite links also increased with predator generality in most webs (Fig. 2). This is consistent with results of several comparative studies that show a link between predator generality (diet breadth) and parasite species richness (Bell and Burt 1991, Guegan and Kennedy 1993, Morand et al. 2000). However, the lack of such a relationship in other comparative studies (Gregory et al. 1991, Poulin 1995, Watve and Sukumar 1995) suggests that a predator's diet may not be an important driver of its parasite richness in all parasite-host systems. This might also be the case of the Otago and Quick Pond food webs where the relationship between a predator's generality and the number of transmission links was absent. However, both webs show the same general trends but low numbers of data points and some outliers may confound the general pattern (this also applies to the Takvatn web in Fig. 1). Overall, there is considerable scatter in most relationships and some of the separate linear regressions gave relatively low $\mathrm{r}^{2}$-values (Table 3), indicating that there are also other factors driving these relationships. One of these factors may be related to the host specificity of parasites. Not all predators will be equally suited as hosts because parasites usually differ in their degree of host specificity (parasite generality or host range; Poulin 2007). Hence, two predators may acquire different parasite species, even if they share the same prey range, and this probably underlies some of the residual noise in the relationships in Fig. 2. Some predators in our webs do not acquire trophically transmitted parasites at all via the prey they consume (and were thus excluded from the analysis), for example because certain taxa generally do not serve as hosts due to phylogenetic constraints. Hence, predator generality alone does not determine infection risk, a predator has also to belong to a higher taxon actually explored by parasites as hosts. Within generally suitable taxa, predator generality will be a strong driver of infection risk as our analyses suggest, probably further mediated by the host specificity of parasites. This interplay of parasite host specificity and predator generality would be interesting to explore but we lack sufficient data for our food webs to investigate this further. More studies are needed to evaluate the generality of the relationship between parasite species richness and predator specialisation.

The high proportion of links leading to predation in the predator-parasite sub webs suggests that predation may constitute a significant source of mortality for parasites. For individual parasite species, this predation pressure might be substantial, given that the average number of predator species ranges from about 4 to 14 predators per parasite life-cycle stage (Fig. 3). The notable differences in predation levels among the food webs are clearly linked to the size of the respective food webs. However, there is little information on the actual magnitude of predation on parasites and on its consequences for parasite population dynamics. Predators can consume a large fraction of free-living stages, leading to reduced infection levels in down-stream hosts (Thieltges et al. 2008a, Orlofske et al. 2012) but we know far less about the effects of concomitant predation on parasite 

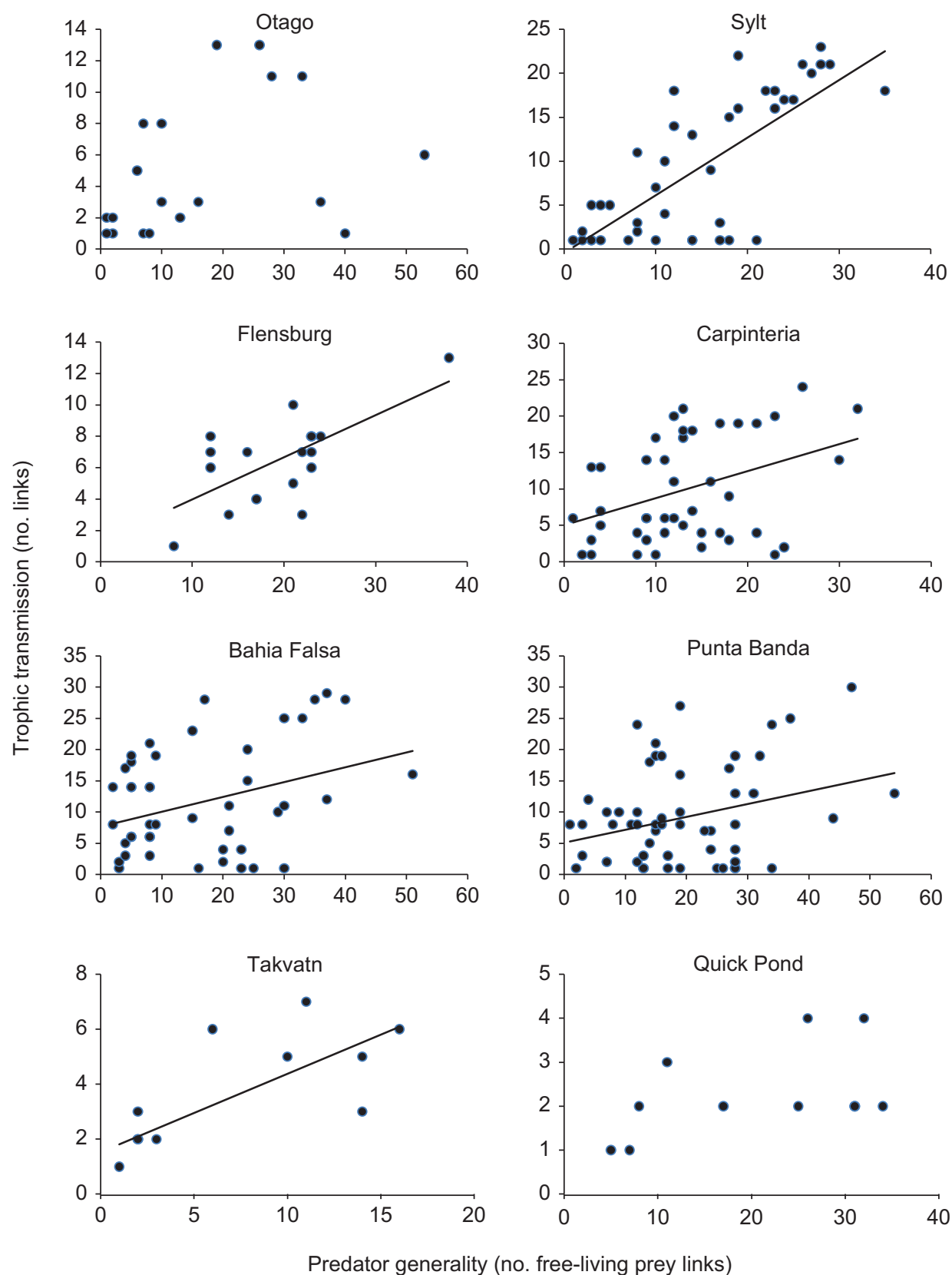

Figure 2. Relationship between predator generality (no. of prey species preyed on per predator in predator-prey sub web) and the vulnerability of predators to becoming infected during predation events (no. links in predator-parasite sub web leading to transmission). Data based on predators that serve as host for at least one trophically transmitted parasite. Note the different scales on axes. Lines indicate the best fit of significant regressions (Sylt: $y=-0.425+0.656 x$; Flensburg y $=1.306+0.268 x$; Carpinteria: $y=5.051+0.370 x$; Bahia Falsa: $y=7.682+0.238 x$; Punta Banda: $y=5.072+0.207 x$; Takvatn: $y=1.520+0.285 x)$. Regression statistics and sample sizes in Table 3 .

transmission and population dynamics. However, the various kinds of predation on parasites can all be expected to affect parasite population dynamics and models of parasite population dynamics would gain from incorporating predator-parasite interactions to explore their actual relevance for specific parasite-host systems (Johnson et al. 2010). In addition to predation, parasite population dynamics are also strongly affected by successful transmission, e.g. of trophically-transmitted parasite life-cycle stages to their down-stream hosts. Overall, trophically transmitted life-cycle stages used, on average, a substantial proportion of predation links in the eight food-webs (44-79\%; Table 1), suggesting that they are well embedded in the respective ecosystems. For established parasites with an evolutionary history of host adaptations, this is probably not surprising. However, the situation will be different for recent invasions of parasites or potential hosts, with likely effects on food web structure. However, only a few studies have tried to quantify actual transmission rates to down-stream hosts (Zander et al. 1994, Amundsen et al. 2003) or investigated the potential effects of invasive species 


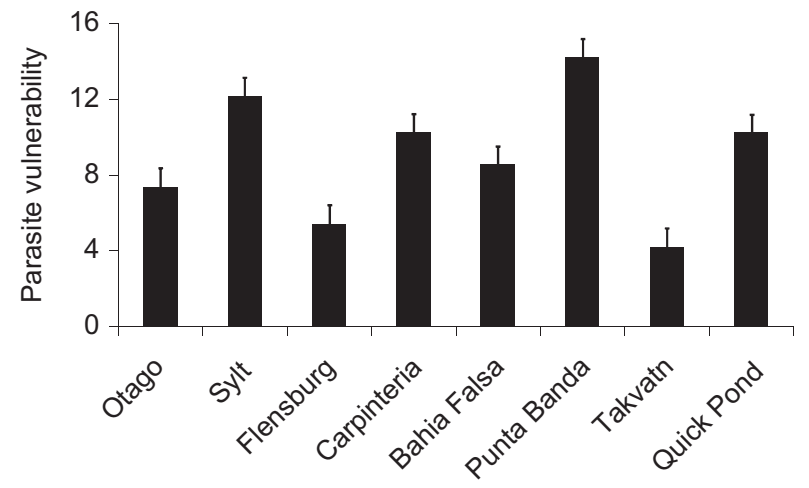

Figure 3. Mean vulnerability (no. of predators) (+ SE) per individual parasite life-cycle stage in the eight predator-parasite sub webs. No. of parasite life-cycle stages in Table 1.

on food web structure (Lafferty and Kuris 2009, Amundsen et al. 2013). Further studies are needed to quantify the actual loss and gain in transmission through predator-parasite interactions in food webs.

Finally, on the level of the entire food web, we found evidence for the prediction that the mean vulnerability of parasites increases with the free-living predator diversity of the food web (Fig. 4). This relationship was statistically significant in the case of the vulnerability of parasites to concomitant predation (both for all life-cycle stages and for trophically transmitted stages only) and suggestive for the vulnerability of free-living stages. If there is an increase in vulnerability of free-living infective stages with free-living diversity, this would support the hypothesis that the transmission of free-living stages of a parasite could decline in high-diversity communities. However, because vulnerability does not directly correspond to predation rates, the impact of predation on parasites will ultimately be determined more by the total abundance of these predators and their rates of predation on infective stages. Although overall levels of predation on parasites might increase with predator richness of food webs, opportunities for transmission also increase as suggested by the significant positive relationship between predator diversity and the mean number of trophic transmission links per tropically transmitted stage. In fact, the number of trophic transmission links increased with predator diversity at approximately the same rate as did parasite vulnerability when considering only trophically transmitted life-cycle stages. This may reflect selection for increased down-stream host generality by parasites in food webs with diverse predator communities. These potentially contrasting effects emphasize the complexity and scale-dependence of the diversity-disease relationship. While increases in host diversity have the potential to limit parasite transmission at a local scale (Keesing et al. 2010), higher host diversity can also facilitate increases in parasite colonization and diversity by adding new trophic pathways (Hechinger and Lafferty 2005, Hudson et al. 2006, Johnson and Thieltges 2010).
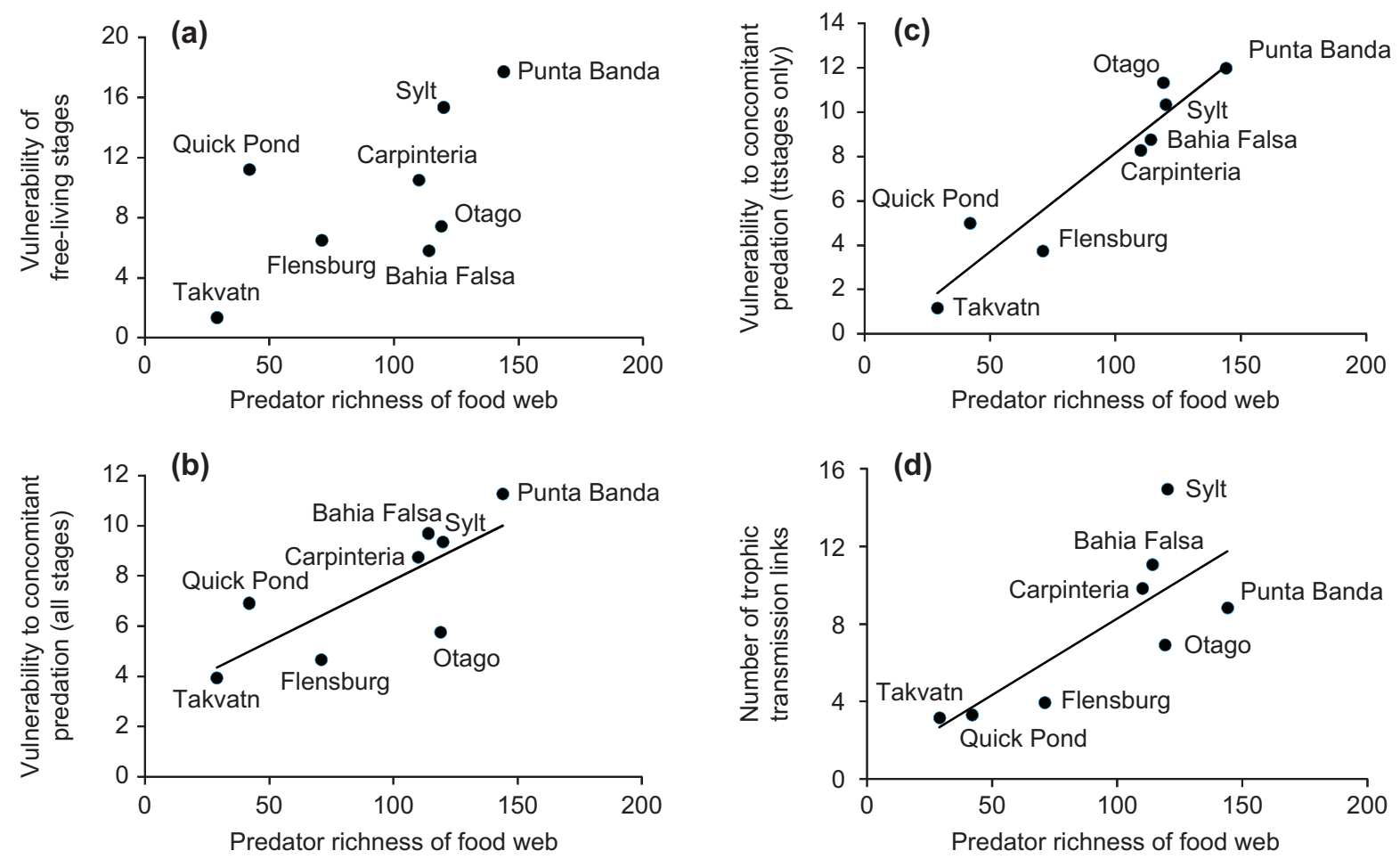

Figure 4. Relationship between total predator richness per food web and (a) vulnerability of free-living stages per parasite life-cycle stage considering free-living stages only; (b) vulnerability to concomitant predation per parasite life-cycle stage (total no. links/no. of parasite life-cycle stages) considering all parasite life-cycle stages; (c) vulnerability to concomitant predation per parasite life-cycle stage considering only trophically transmitted (tt) life-cycle stages (total no. links/no. of trophically transmitted parasite life-cycle stages); and (d) number of trophic transmission links per trophically transmitted life-cycle stage (total no. of links/no. of trophically transmitted stages). Lines indicate the best fit of significant regressions (b) $y=2.946+0.049 x ;(c) y=-0.746+0.089 x$; (d) $y=0.4116+0.0786 x)$. 


\section{Conclusion}

Our analyses show that food-web studies can inform us about the interplay between predation and transmission of parasites in natural systems. Our data suggest that predation on parasites has important implications for both predators and prey. For predators, parasites often constitute an additional food source that has largely been omitted in previous food-web studies. And for parasites, predation on hosts or free-living stages is possibly a strong regulating factor. Our analyses also suggest that network analyses neglecting parasites present a rather distorted numerical picture, potentially misleading our conclusions about the functioning of ecosystems. However, these inferences are based on topological webs, which do not include information on the actual strength of interactions among nodes. What is needed next is more detailed information on energy flows through predator-parasite sub webs. The present data suggest that this will be a worthwhile effort on the way to a more complete and general understanding of ecosystem properties and functioning.

Acknowledgements - We thank E. Mordecai and J. McLaughlin for comments on the paper. This work was conducted as a part of the Parasites and Foodwebs Working Group supported by the National Center for Ecological Analysis and Synthesis, a Center funded by NSF (grant no. DEB-0553768), the Univ. of California, Santa Barbara and the State of California. DWT acknowledges support by a fellowship from the German Research Foundation (DFG) (Th 1361/1-1). PTJJ was supported by a grant from NSF (DEB0553768) and a fellowship from the David and Lucile Packard Foundation. RFH and KDL have benefited from NSF-NIH EID grants (DEB-0224565, OCE-1115965) and PAA from a grant from the Norwegian Research Council (NFR 213610/F20). Any use of trade, product or firm names in this publication is for descriptive purposes only and does not imply endorsement by the US government. Finally, we thank the reviewers for their thoughtful comments the manuscript.

\section{References}

Allesina, S. et al. 2008. A general model for food web structure. - Nature 320: 658-661.

Amundsen, P.-A. et al. 2003. Seasonal and ontogenetic dynamics in trophic transmission of parasites. - Oikos 102: 285-293.

Amundsen, P.-A. et al. 2009. Food web topology and parasites in the pelagic zone of a subarctic lake. - J. Anim. Ecol. 78: 563-572.

Amundsen, P.-A. et al. 2013. New parasites and predators follow the introduction of two fish species to a subarctic lake: implications for food-web structure and functioning. - Oecologica 171: 993-1002.

Anderson, R. M. et al. 1978. Concomitant predation and infection processes: an experimental study. - J. Anim Ecol. 47: 891-911.

Bell, G. and Burt, A. 1991. The comparative biology of parasite species diversity: internal helminths of freshwater fish. - J. Anim. Ecol. 60: 1047-1064.

Chen, H.-W. et al. 2008. Network position of hosts in food webs and their parasite diversity. - Oikos 117: 184-1855.

Cohen, J. E. 1978. Food webs and niche space. - Princeton Univ. Press.

Dobson, A. P. et al. 2006. Parasites and food-webs. - In: Pascual, M. and Dunne, J. A. (eds), Ecological networks: linking structure to dynamics. Oxford Univ. Press, pp. 119-135.
Dunne, J. A. 2006. The network structure of food-webs. - In: Pascual, M. and Dunne, J. A. (eds), Ecological networks: linking structure to dynamics. Oxford Univ. Press, pp. 27-86.

Dunne, J. A. et al. 2005. Modelling food-web dynamics: complexity-stability implications. - In: Belgrano, A. et al. (eds), Aquatic food webs - an ecosystem approach. Oxford Univ. Press, pp. 117-129.

Gregory, R. D. et al. 1991. Life history, ecology and parasite community structure in Soviet birds. - Biol. J. Linn. Soc. 43: 249-262.

Guegan, J.-F. and Kennedy, C. R. 1993. Maximum local helminth parasite comminity richness in British freshwater fish: a test of the colonisation time hypothesis. - Parasitology 106: 91-100.

Hechinger, R. F. and Lafferty, K. D. 2005. Host diversity begets parasite diversity: bird final hosts and trematodes in snail intermediate hosts. - Proc. Biol. Sci. 272: 1059-1066.

Hechinger, R. F. et al. 2011. Food webs, including infectious agents, biomass, body sizes and life-stages, for three estuaries in California and Baja California. - Ecology 92: 791-792.

Hernandez, A. D. and Sukhdeo, M. V. K. 2008. Parasites alter the topology of a stream food web across seasons. - Oecologia 156: 613-624.

Hudson, P. J. et al. 2006. Is a healthy ecosystem one that is rich in parasites? - Trends Ecol. Evol. 21: 381-385.

Huxham, M. et al. 1995. Parasites and food-web patterns. - J. Anim. Ecol. 64: 168-176.

Johnson, P. T. J. and Thieltges, D. W. 2010. Diversity, decoys and the dilution effect: how ecological communities affect disease risk. - J. Exp. Biol. 213: 961-970.

Johnson, P. T. J. et al. 2010. When parasites become prey: ecological and epidemiological significance of eating parasites. - Trends Ecol. Evol. 25: 362-371.

Kaplan, A. T. et al. 2009. Small estuarine fishes feed on large trematode cercariae: lab and field observations. - J. Parasitol. 95: 477-480.

Keesing, F. et al. 2010. Impacts of biodiversity on the emergence and transmission of infectious diseases. - Nature 468: 647-652.

Kuris, A. M. et al. 2008. Parasite and free-living biomass in estuaries: implications for ecosystem energetics. - Nature 454: 515-518.

Lafferty, K. D. 1999. The evolution of trophic transmission. - Parasitol. Today 15: 111-115.

Lafferty, K. D. and Morris, A. K. 1996. Altered behavior of parasitized killifish increases susceptibility to predation by bird final hosts. - Ecology 77: 1390-1397.

Lafferty, K. D. and Kuris, A. M. 2009. Parasites reduce food web robustness because they are sensitive to secondary extinction as illustrated by an invasive estuarine snail. - Phil. Trans. R. Soc. B 364: 1659-1663.

Lafferty, K. D. et al. 2006a. Parasites dominate food web links. - Proc. Natl Acad. Sci. USA 103: 11211-11216.

Lafferty, K. D. et al. 2006b. Food webs and parasites in a salt marsh ecosystem. - In: Collinge, S. and Ray, C. (eds), Disease ecology: community structure and pathogen dynamics. Oxford Univ. Press, pp. 119-134.

Lafferty, K. D. et al. 2008. Parasites in food webs: the ultimate missing links. -Ecol. Lett. 11: 533-546.

Marcogliese, D. J. and Cone, D. K. 1997. Food webs: a plea for parasites. - Trends Ecol. Evol. 12: 320-325.

May, R. M. 1973. Stability and complexity in model ecosystems. - Princeton Univ. Press.

Morand, S. et al. 2000. Endoparasite species richness of New Caledonian butterfly fishes: host density and diet matter. - Parasitology 121: 65-73.

Mouritsen, K. N. and Jensen, T. 2006. The effect of Sacculina carcini infections on the fouling, burying behaviour and condition of the shore crab, Carcinus maenas. - Mar. Biol. Res. 2: $270-275$. 
Mouritsen, K. N. et al. 2011. Food web including metazoan parasites for an intertidal ecosystem in New Zealand. - Ecology 92: 2006.

Orlofske, S. A. et al. 2012. Parasite transmission in complex communities: predators and alternative hosts alter pathogenic infections in amphibians. - Ecology 93: 1247-1253.

Pimm, S. L. et al. 1991. Food web patterns and their consequences. - Nature 350: 669-674.

Poulin, R. 1995. Phylogeny, ecology, and the richness of parasite communities in vertebrates. - Ecol. Monogr. 65: 283-302.

Poulin, R. 2007. Evolutionary ecology of parasites. - Princeton Univ. Press.

Preston, D. L. et al. 2012. Food web including infectious agents for a California freshwater pond. - Ecol. Arch. E093-153-D1, Ecology 93: 1760.

Preston, D. L. et al. 2013. Biomass and productivity of trematode parasites in pond ecosystems. - J. Anim. Ecol. 82: 509-517.

Rossiter, W. and Sukhdeo, M. V. K. 2011. Exploitation of asymmetric predator-prey interactions by trophically transmitted parasites. - Oikos 120: 607-614.

Sánchez, M. I. et al. 2009. Neurological and physiological disorders in Artemia harboring manipulative cestodes. - J. Parasitol. 95: 20-24.
Thieltges, D. W. et al. 2008a. The role of biotic factors in the transmission of free-living endohelminth stages. - Parasitology 135: 407-426.

Thieltges, D. W. et al. 2008b. Production of marine trematode cercariae - a potentially overlooked path of energy flow in benthic systems. - Mar. Ecol. Prog. Ser. 372: 147-155.

Thieltges, D. W. et al. 2011. Food web including metazoan parasites for a tidal basin in Germany/Denmark. - Ecology 92: 2005.

Thompson, R. M. et al. 2005. Importance of parasites and their life cycle characteristics in determining the structure of a large marine food web. -J. Anim. Ecol. 74: 77-85.

Watve, M. G. and Sukumar, R. 1995. Parasite abundance and diversity in mammals: correlates with host ecology. - Proc. Natl Acad. Sci. USA 92: 8945-8949.

Williams, R. J. and Martinez, N. D. 2000. Simple rules yield complex food webs. - Nature 404: 180-183.

Wood, M. J. 2007. Parasites entangled in food webs. - Trends Parasitol. 23: 8-10.

Zander, C. D. et al. 1994. Parasite transfer from crustacean to fish hosts in the Lübeck Bight, SW Baltic Sea. - Helgol. Meeresunt. 48: 89-105.

Zander, C. D. et al. 2011. Food web including metazoan parasites for a brackish shallow water ecosystem in Germany/Denmark. - Ecology 92: 2007. 